\title{
Airborne Chloride Intensity and Chloride Ion Penetration into Mortar Specimen in Thailand
}

\author{
Rungrawee Wattanapornprom ${ }^{1, *}$, Pakpoom Limtong ${ }^{2}$, Tetsuya Ishida ${ }^{2}$, \\ Phoonsak Pheinsusom ${ }^{1}$, and Withit Pansuk ${ }^{1}$ \\ 1 Innovative Construction Materials Research Unit, Department of Civil Engineering, Faculty of Engineering, \\ Chulalongkorn University, Bangkok, Thailand \\ 2 Department of Civil Engineering, University of Tokyo, Tokyo, Japan \\ *E-mail: Rungrawee.w@gmail.com (Corresponding author)
}

\begin{abstract}
The Southern and Eastern parts of Thailand have long coastlines and are located in a hot and humid climate zone. A concrete structure in such environmental conditions tends to deteriorate owing to the corrosion of the steel reinforcement by airborne chloride. The concentration of airborne chloride varies by location and exposure conditions in each country. Thus, when designing concrete structures in such environments, the amount of airborne chloride and the concrete mix proportions should be carefully considered. However, the study of airborne chloride intensity and penetration in Thailand is still limited. This study examined the airborne chloride in the atmosphere in Phuket, Phang-Nga, and Chonburi Province. The amount of airborne chloride was checked every 1-3 months during the test period. Although the distances from the seashore are almost the same in all three locations, the airborne chloride intensity varied owing to the different exposure directions and environmental conditions. Additionally, analysis of mortar specimens with different sources of fly ash installed in Chonburi province to assess the airborne chloride penetration behavior showed that airborne chloride concentration varied with the breaking wave height, rainfall, and varied penetration rate based on the source of fly ash.
\end{abstract}

Keywords: Airborne chloride, generation, durability, chloride penetration, pozzolan.

ENGINEERING JOURNAL Volume 24 Issue 2

Received 11 June 2019

Accepted 11 February 2020

Published 31 March 2020

Online at https://engj.org/

DOI:10.4186/ej.2020.24.2.87 


\section{Introduction}

Airborne salt (sea salt aerosol or airborne chloride; ABS) are chloride particles generated by breaking waves and are transported in the atmosphere by the wind flow. ABS particles contain around 3-3.5\% chloride, similar to the concentration in seawater [1, 2]. In a marine environment, concrete structures encounter corrosion of steel reinforcements due to airborne chloride, even though the structures are not directly in contact with seawater [3]. The ABS carried inland by wind flow to a target concrete structure, binds and accumulates on the concrete surface, penetrates through pores, and initiates the depassivation of reinforcing steel inside concrete, which leads to steel corrosion.

Unlike concrete structures in the splash or tidal zones, surroundings and environmental conditions play an important role in airborne chloride generation and transportation [2]. ABS particles are generated when sea waves reach the seashore or an obstacle [4]. The size of ABS particles mainly depends on the weather, wave conditions, and coastal topology [2]. It has been reported that obstacles such as wave breakers or cliffs contribute to a higher amount of large size airborne chloride [4]. Larger particles of airborne chloride rapidly drop vertically owing to gravity. However, smaller particles can be transported by the wind across long distances.

Previous research shows that ABS intensity varies in each area owing to different environmental conditions [46]. As a result, the amount of ABS in each area differs. Table 1 shows the change in ABS intensity based on the difference in exposure location and distance from the coastline.

Table 1. Airborne chloride collection method and duration in different locations.

\begin{tabular}{lccccc}
\hline \multicolumn{1}{c}{ Reference } & $\begin{array}{c}\text { Duration } \\
\text { (months) }\end{array}$ & $\begin{array}{c}\text { Collection } \\
\text { method }\end{array}$ & $\begin{array}{c}\text { Distance from } \\
\text { the coastline (m) }\end{array}$ & Location & $\begin{array}{c}\text { Airborne chloride } \\
\text { amount } \\
\text { (mg.-Cl/dm } / \text { day) }\end{array}$ \\
\hline PWRI (1988) [5] & $12-36$ & Capture tank & $0-1000$ & Japan & $0.00-146.10$ \\
\hline $\begin{array}{l}\text { Nakamura et.al (2014) } \\
\text { [6] }\end{array}$ & 12 & Capture tank & 0 & Japan & $0.01-5.95$ \\
\hline $\begin{array}{l}\text { Meira (2004) [7] } \\
\text { Hossain \& Easa }\end{array}$ & 17 & Wet candle & $10-1100$ & Brazil & $0.04-2.79$ \\
\hline $\begin{array}{l}\text { Mustafa \& Yusof } \\
\text { (1994) [9] }\end{array}$ & 12 & Wet candle & $93-7012$ & Bangladesh & $0.01-0.54$ \\
\hline \begin{tabular}{l} 
Saeki (2010) [10] \\
\hline Chen et.al [11]
\end{tabular} & 12 & Mortar chip & $0-4500$ & Japan & $0.05-11.27$ \\
\hline
\end{tabular}

*Modified capture tank.

The Southern and Eastern parts of Thailand have long coastlines and are located in hot and humid climate zones. A concrete structure in such environmental conditions tends to deteriorate owing to the corrosion of the steel reinforcement by airborne chloride. If the actual amount of the ABS deposited on the concrete structure is known, it will be beneficial to design durable structures. However, the long-term recorded data of airborne chloride in Thailand's coastal area are still limited. This study conducts an exposure test to check the amount of airborne chloride in select locations.

Many researchers have conducted exposure tests by using several methods to measure the amount of ABS at a specified position. The dry gauze method, standardized as JIS Z 2382, is a conventional method. However, this method is recommended to capture airborne chloride only during a few hours [12]. In 1988, the airborne chloride capture tank method determined the amount of ABS over an extended period (more than one month) [5]. This method has been widely used in Japan [6]. In other countries, some researchers alternately used the wet candle following ASTM G140 to check the ABS [7, 8, 9]. The capture tank and the wet candle, however, require large spaces for the equipment, which cannot be restricted to a precise position.

Additionally, an exposure experiment was conducted by introducing a thin mortar plate of size $40 \times 40 \mathrm{~mm}^{2}$, which is smaller than the capture tank equipment or wet candle [10]. In 2017, the thin mortar plate and tank methods were compared. The results showed that the amount of ABS obtained by the tank and mortar chip methods was similar when the equipment was installed in the same position.

Consequently, it is easy to check the amount of ABS at a specified position for which the thin mortar chip method was selected. In this study, mortar specimens with different sources of fly ash were installed in Chonburi province to clarify the airborne chloride penetration behavior. 


\section{Experiment Methodology}

\subsection{Airborne Chloride Collection}

There are several methods to measure the amount of airborne chloride at a specified location [7, 13, 14]. The airborne chloride collection methods described can determine the relative amount of chloride at specific locations and times. Owing to the limitation of space at the exposure site, the mortar chip was used as the chloride collection instrument $[10,13]$. The size of the mortar chip in this test was $40 \times 40 \mathrm{~mm}^{2}$, with a thickness of $5 \mathrm{~mm}$ and the weight of water to concrete ratio (W/C) around 0.60 . The mortar chip specimen was produced by DenkaRenotec Co. ltd. (Fig. 1) without any initial chloride content.

Mortar chip specimens were placed at different positions to check the airborne chloride intensity around the exposure sites. After the exposure, each mortar chip was ground into a powder with a grinder. To find the amount of airborne chloride, we titrated the mixture of water and mortar powder with silver nitrate solution $\mathrm{AgNO}_{3}$ [15]. The chloride deposition amount was checked every 21-44 days during the testing period. The mortar chips were placed near the sea in the Phuket, Phang-Nga, and Chonburi provinces of Thailand. The exposure site and durations are listed in Table 2, and the exposure position is shown in Fig. 2.

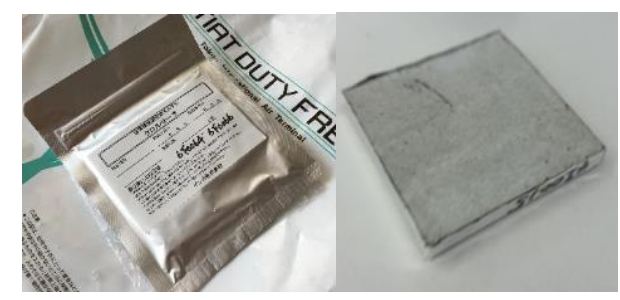

Fig. 1. Mortar chip used in the experiment.

Table 2. Exposure site, dates, and durations.

\begin{tabular}{lccr}
\hline \multicolumn{1}{c}{ Area } & Distance from coast $(\mathrm{m})$ & Height $(\mathrm{m})$ & Exposure duration \\
\hline Phuket Province & 30 & 2.0, 14.0, and 15.5 & January-June 2017 \\
\hline Phang Nga Province & 30 & 2 & January 2017-December 2018 \\
\hline $\begin{array}{l}\text { Chonburi Province } \\
\text { (mortar chip) }\end{array}$ & 30 & 2 & April 2018-January 2019 \\
\hline $\begin{array}{l}\text { Chonburi Province } \\
\text { (mortar specimen) }\end{array}$ & 30 & 2 & April 2018-April 2019 \\
\hline
\end{tabular}



Fig. 2. Exposure position in Thailand (Google Map 2019).

\subsection{Airborne Chloride Penetration Experiment}

\subsubsection{Materials}

1) Cement (OPC)

Type I ordinary Portland cement conforming to ASTM C150 was used in this study. The specific gravity of cement is 3.15 .

2) Fly ash (FA)

The fly ash used in this study was obtained from three different sources, as shown in Table 3. From the chemical properties, the fly ash from each source can be classified as class $\mathrm{C}$ fly ash conforming to ASTM C 618 [16]; $\left(\mathrm{SiO}_{2}+\mathrm{Al}_{2} \mathrm{O}_{3}+\mathrm{Fe}_{2} \mathrm{O}_{3}\right.$ over than between $50 \%$ and $\left.70 \%\right)$

\section{3) Fine aggregate}

Natural river sand with a fineness modulus of 2.65 with a maximum size of $4.75 \mathrm{~mm}$ and an aggregate absorption value of $0.51 \%$ was used as the fine aggregate. 


\subsubsection{Specimen preparation}

The chloride ion ingression mechanisms were studied by casting two sets of $10 \times 10 \times 10 \mathrm{~cm}^{3}$ mortar specimens with four different mix proportions (Table 4) and curing them by submerging them in water in the laboratory.

After curing the mortar specimens for 28 days, each specimen was coated with epoxy on five surfaces, leaving one surface exposed to analyze one-dimensional chloride penetration, as shown in Fig. 3.
Specimens were placed at the site and exposed to the actual environment in Amphor Sattaheep, Chonburi province. The specimens and the exposure site in the test are shown in Fig. 4.

After three, six, nine, and twelve months of exposure, the specimens were drilled to get the powder at different depths, as shown in Fig. 5.

The powder specimens were titrated with silver nitrate solution $\left(\mathrm{AgNO}_{3}\right)$ [15] to determine the chloride concentration at each depth.

Table 3. Source and basic properties of Fly ash*.

\begin{tabular}{|c|c|c|c|c|c|}
\hline Source & Power plant area & $\mathrm{SiO}_{2}+\mathrm{Al}_{2} \mathrm{O}_{3}+\mathrm{Fe}_{2} \mathrm{O}_{3}$ & Class & $\begin{array}{c}\text { Specific } \\
\text { gravity }\end{array}$ & $\begin{array}{l}\text { Fineness air } \\
\text { permeability } \\
\left(\mathrm{cm}^{2} / \mathrm{g}\right)\end{array}$ \\
\hline $\begin{array}{l}\text { Mae Moh Power plant } \\
\text { (Mae Moh FA) }\end{array}$ & $\begin{array}{l}\text { Lampang Province } \\
\text { (Northern } \\
\text { Thailand) } \\
\end{array}$ & $68.26 \%$ & $\mathrm{C}$ & 2.22 & 2,690 \\
\hline $\begin{array}{l}\text { BLCP Power plant } \\
\text { (BLCP FA) }\end{array}$ & $\begin{array}{l}\text { Rayong Province } \\
\text { (Eastern Thailand) }\end{array}$ & $62.10 \%$ & $\mathrm{C}$ & 2.35 & 3,000 \\
\hline $\begin{array}{c}\text { Shikoku Electric Power } \\
\text { Co., Inc. } \\
\text { (Japan FA) }\end{array}$ & Takamatsu, Japan & $66.50 \%$ & $\mathrm{C}$ & 2.55 & 2,589 \\
\hline
\end{tabular}

*The chemical properties are from the test sample only.

Table 4. Mix proportions of the mortar specimens (per $\mathrm{m}^{3}$ ).

\begin{tabular}{ccccccc}
\hline Mix No. & Definition & W/B & $\begin{array}{c}\text { Cement } \\
(\mathbf{k g})\end{array}$ & $\begin{array}{c}\text { Fly } \\
\mathbf{a s h} \\
(\mathbf{k g})\end{array}$ & $\begin{array}{c}\text { Water } \\
\mathbf{( k g})\end{array}$ & $\begin{array}{c}\text { Sand } \\
(\mathbf{k g})\end{array}$ \\
\hline 1 & OPC 100\% & 0.55 & 590 & 0 & 325 & 1280 \\
\hline 2 & OPC 70\%, Mae Moh 30\% & 0.55 & 395 & 170 & 315 & 1280 \\
\hline 3 & OPC 70\%, BLCP 30\% & 0.55 & 395 & 170 & 315 & 1280 \\
\hline 4 & OPC 70\%, Japan 30\% & 0.55 & 395 & 170 & 315 & 1280 \\
\hline
\end{tabular}

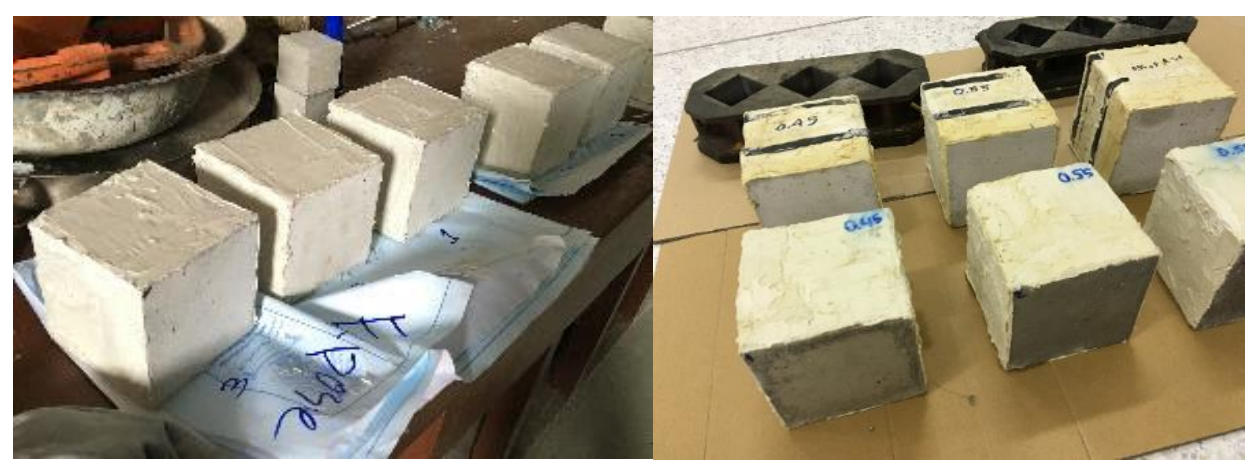

Fig. 3. Mortar specimens coated with epoxy resin. 



Fig. 4. On-site exposure specimens in Chonburi Province.
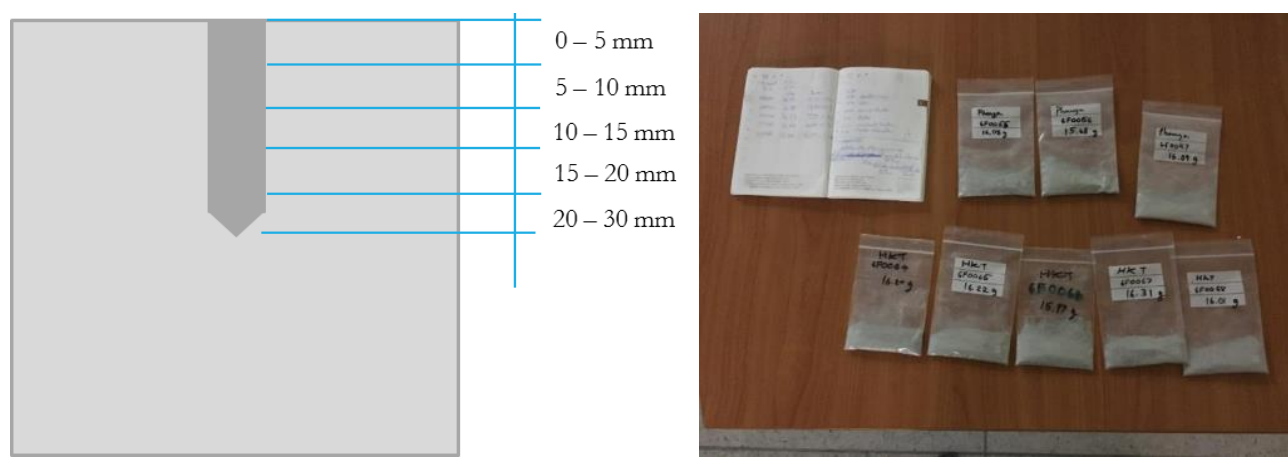

Fig. 5. Drilling depth and powder sample for the experiment.

\section{Exposure Site and Condition}

\subsection{Overall Climate and Exposure Condition in Thailand}

Southern and Eastern Thailand is surrounded by the ocean. The Andaman Sea covers the west coast, and the Gulf of Thailand covers the east coast. Thus, comparatively, the Southern part tends to have higher airborne chloride. The annual South-West monsoon affects Thailand from May to October, and the NorthEast monsoon from November to January [17], as shown in Fig. 6. In the West-coast areas, such as Phuket and Phang-Nga, the South-West monsoon carries moist wind from the Indian Sea. On the other hand, the cold, dry wind from the North-East monsoon cannot fully reach these areas owing to the Gulf of Thailand. Thus, concrete structures in these areas are exposed to a harsh marine environment, with a hot and humid moist climate throughout the year.

\subsection{Phuket}

Kalim beach, on the Andaman Sea coast, was selected as the location to collect the quantity of airborne chloride. The site is located about $30 \mathrm{~m}$ from the sea. Five mortar chips were installed $30 \mathrm{~m}$ from the coast at elevations of 2.0, 14.0, and $15.5 \mathrm{~m}$, as shown in Fig. 7. The mortar chip specimens were exposed to the environment from January to June 2017 in Phuket.



Fig. 6. Annual monsoon in Thailand (modified from the reference) [17]. 


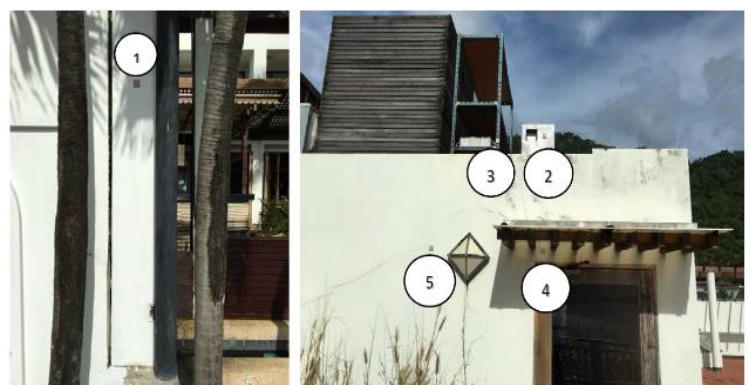

Fig. 7. Mortar chip positions in Phuket site.

The survey of the location showed that there were no obstacles, providing the specimens and equipment with exposure to the wind flow and rainfall to imitate the actual airborne chloride environment. The exposure conditions around the testing location in Phuket are shown in Fig. 8.

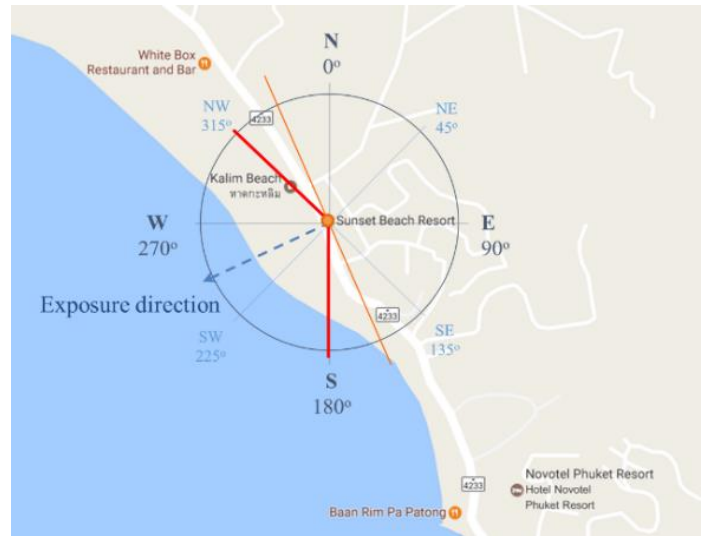

Fig. 8. Map of exposure position and exposure direction in Phuket (from Google maps).

\subsection{Phang-Nga}

Tambon Khok Kloi, Amphoe Takua Thung, PhangNga Province was selected for data collection. Phang-Nga also presents beach coast conditions. Three mortar chips were installed $30 \mathrm{~m}$ from the beach coast at $2.0-\mathrm{m}$ height (Fig. 9). The exposure direction and position are shown in Fig. 10. The exposure duration was between January 2017 and December 2018.

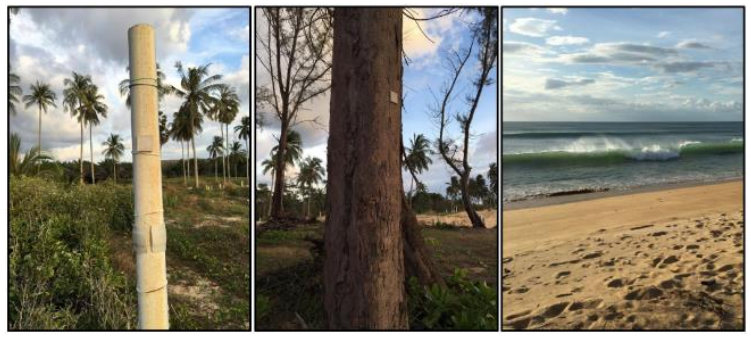

Fig. 9. Mortar chip positions at Phang-Nga site.

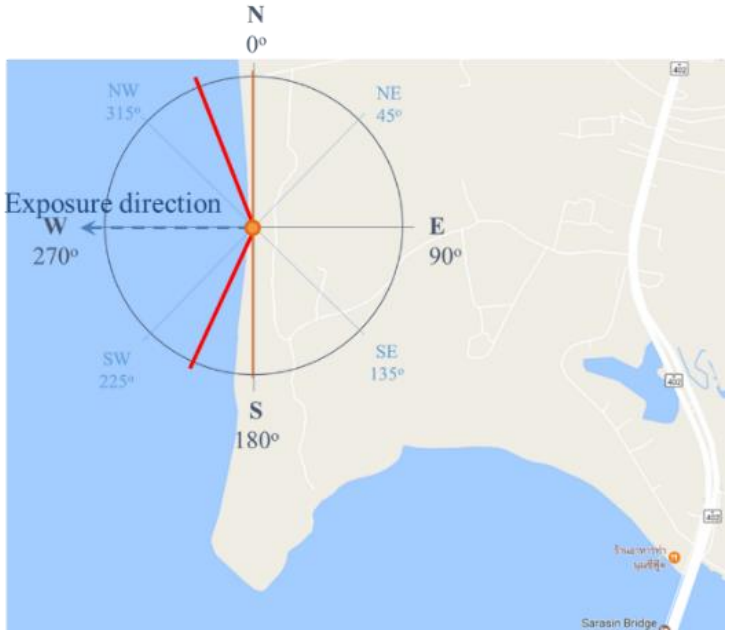

Fig. 10. Map of exposure position and exposure direction in Phang-Nga (from Google maps).

\subsection{Chonburi}

Sattahip beach, Chonburi, was selected to collect the airborne chloride data from and conduct the chloride penetration analysis. Three mortar chips were installed 30 $\mathrm{m}$ from the beach coast at $2.0 \mathrm{~m}$ height (Fig. 9). The mortar chip specimens were exposed from April 2018 to January 2019. Additionally, the mortar specimens with different sources of fly ash were also installed at the same place from April 2018 to April 2019. The exposure direction and position are shown in Fig. 12.

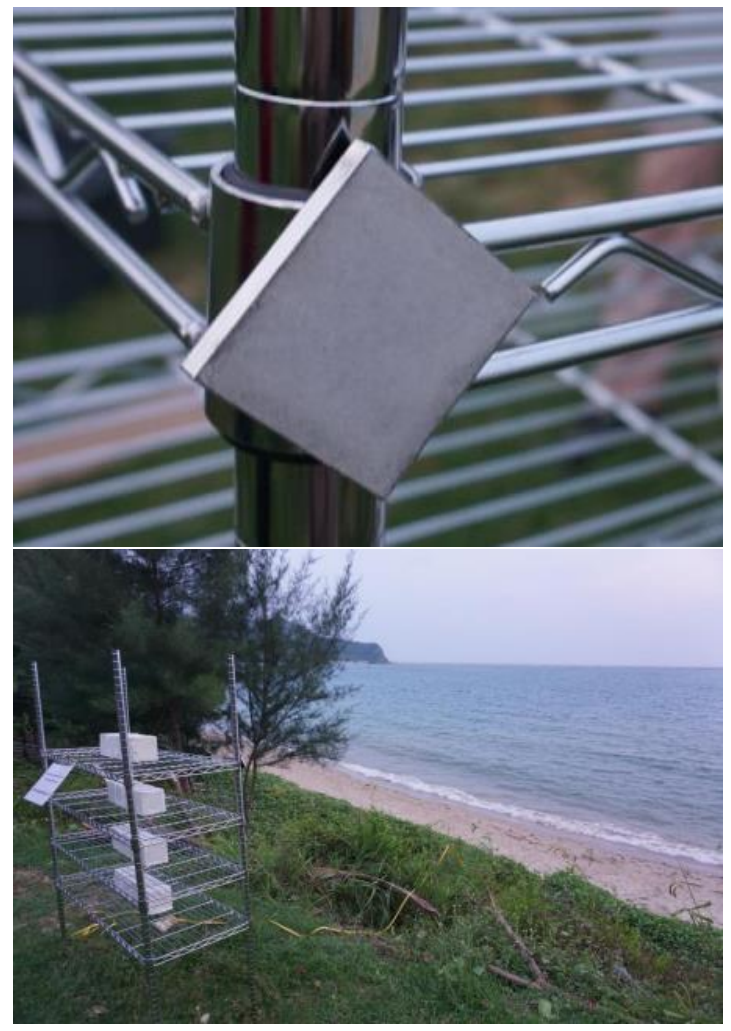

Fig. 11. Mortar chip positions at Chonburi site. 




Fig. 12. Map of exposure position and exposure direction in Chonburi (from Google maps).

\section{Experimental Results and Discussion}

\subsection{Airborne Chloride Intensity}

\subsubsection{Phuket}

The airborne chloride intensity is represented by total chloride content $(-\mathrm{Cl})$ in the mortar chip in unit mdd $\left(\mathrm{mg} / \mathrm{dm}^{2} /\right.$ day). Figure 13 shows the amount of airborne chloride in Phuket.

Previous research has shown that the amount of ABS tends to decrease at higher elevations [14] as wind speed reduces at these positions. However, the experimental results in Phuket from January to May show that the amount of airborne chloride from the mortar chips is almost the same at $2 \mathrm{~m}$ and $15.5 \mathrm{~m}$ elevations.

To examine this, the mortar chip positions were changed for the period from May to June, as shown in Fig. 14. A significant increase in airborne chloride was observed, with a large difference at each height. The survey at the initial position revealed that the vehicles plying on the street resulted in higher wind turbulence at the $2 \mathrm{~m}$ level. It is postulated that despite the lack of obstacles, the moving vehicles can change the direction of wind easily and cause reduction in airborne chloride.

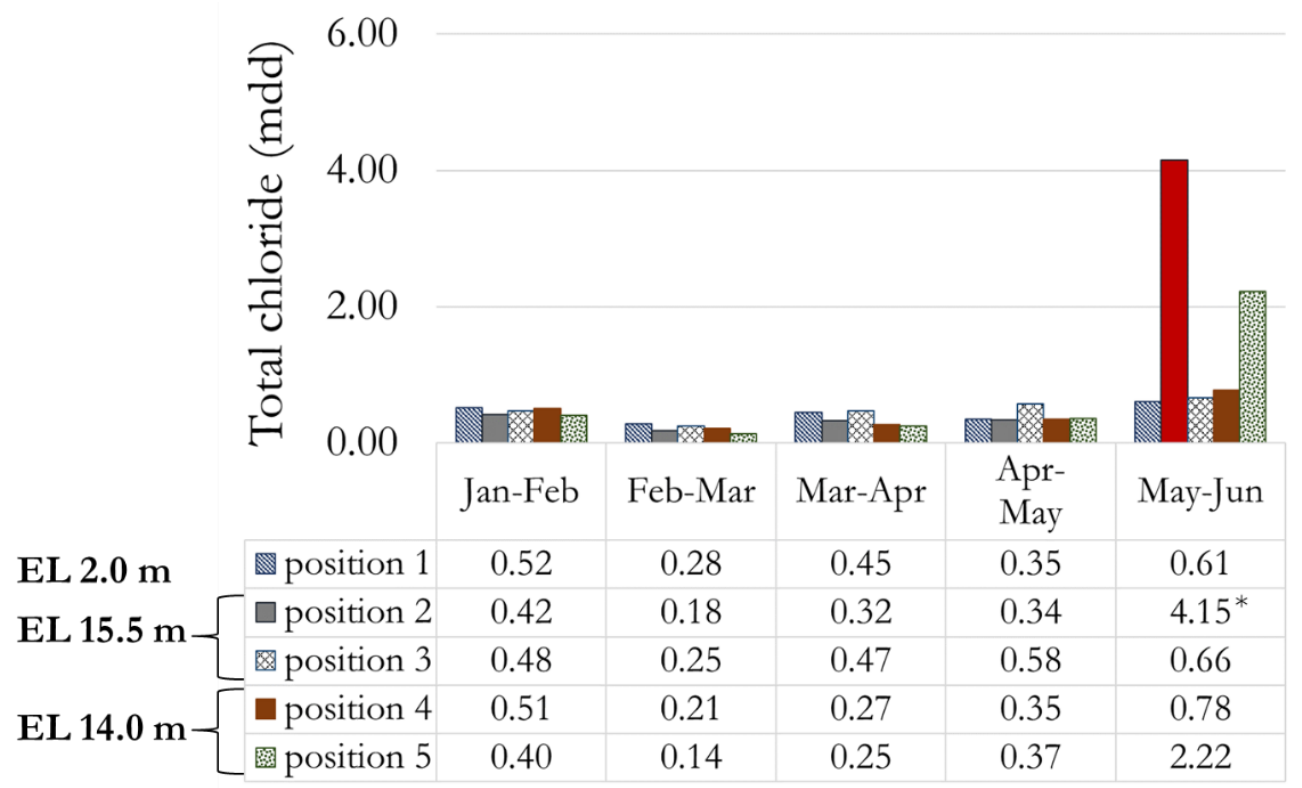

* Changed the position of the mortar chip.

Fig. 13. Airborne chloride in Phuket. 


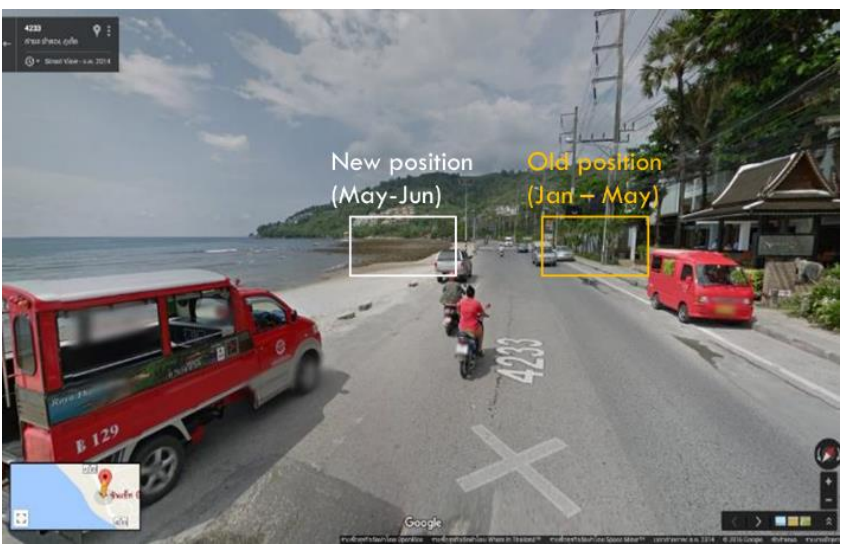

Old position
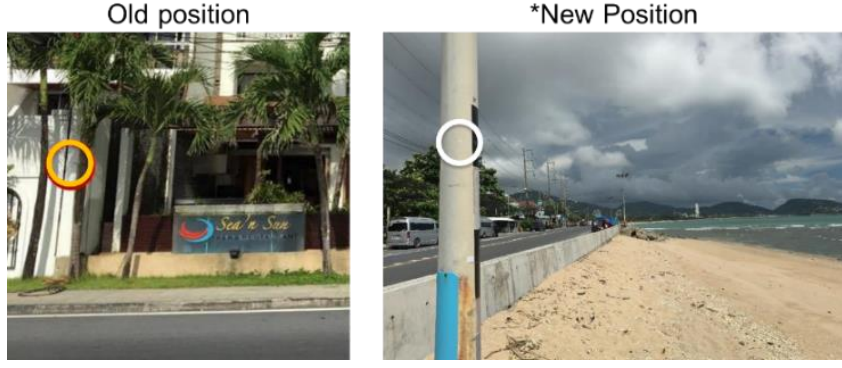

Fig. 14. Mortar chip positions in Phuket in January-May and in May-June.

\subsubsection{Phang-Nga}

Figure 15 shows the amount of airborne chloride in Phang-Nga. From January to May, the airborne chloride intensity in Phang-Nga was around 0.90 to $1.30 \mathrm{mdd}$. However, from May to June, the amount of airborne chloride rapidly increased owing to the significant change in breaking wave height (Fig. 17) in this period. Furthermore, based on Thailand's climate data, it was observed that the amount of airborne chloride was also influenced by the annual South-West monsoon from May to October. The wind from the South-West moves toward Thailand's coastline, thus increasing the wind speed and breaking wave height. As a result, the amount of airborne chloride increases annually from May to October.

\subsubsection{Chonburi}

Figure 16 shows the amount of airborne chloride in Chonburi. Similar to Phang-Nga, the amount of airborne chloride increases from June to August, potentially influenced by the annual South-West monsoon.

\subsubsection{Comparison of ABS amount in Phuket and Phang- Nga Province (January 2017-June 2017)}

The salinity level of the Andaman sea considered in previous studies was examined to compare the amount of ABS in Phuket and Phang-Nga areas [18]. The salinity in the Andaman Basin, which is close to Phuket and PhangNga provinces, was the same as that of these provinces, and slightly varied in each season. Thus, the salinity content could be the main factor affecting the chloride amount.

From the results in Fig. 13 and Fig. 15, at 2 m, the ABS intensity in Phang-Nga is higher than that in Phuket. ABS intensity differs in different areas owing to different exposure directions and conditions, even if the collection method, distance from the seashore, elevation, and exposure period are almost the same. Wind turbulence from the vehicular movement, as explained earlier, is one contributor. However, after changing the mortar chip position, the ABS value in Phang-Nga was higher than in Phuket. This may be because the breaking wave height in Phang-Nga is higher (Fig. 17), resulting in an increase in the amount of airborne chloride [2].

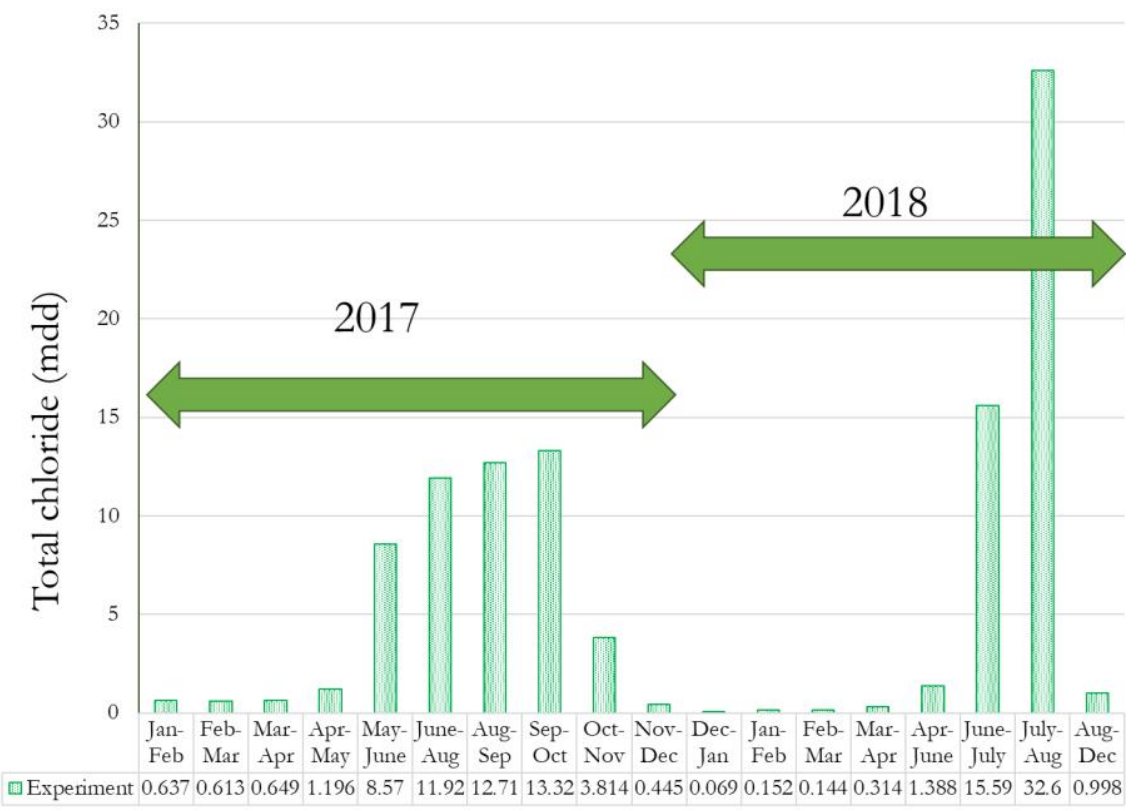

Fig. 15. Airborne chloride in Phang-Nga. 


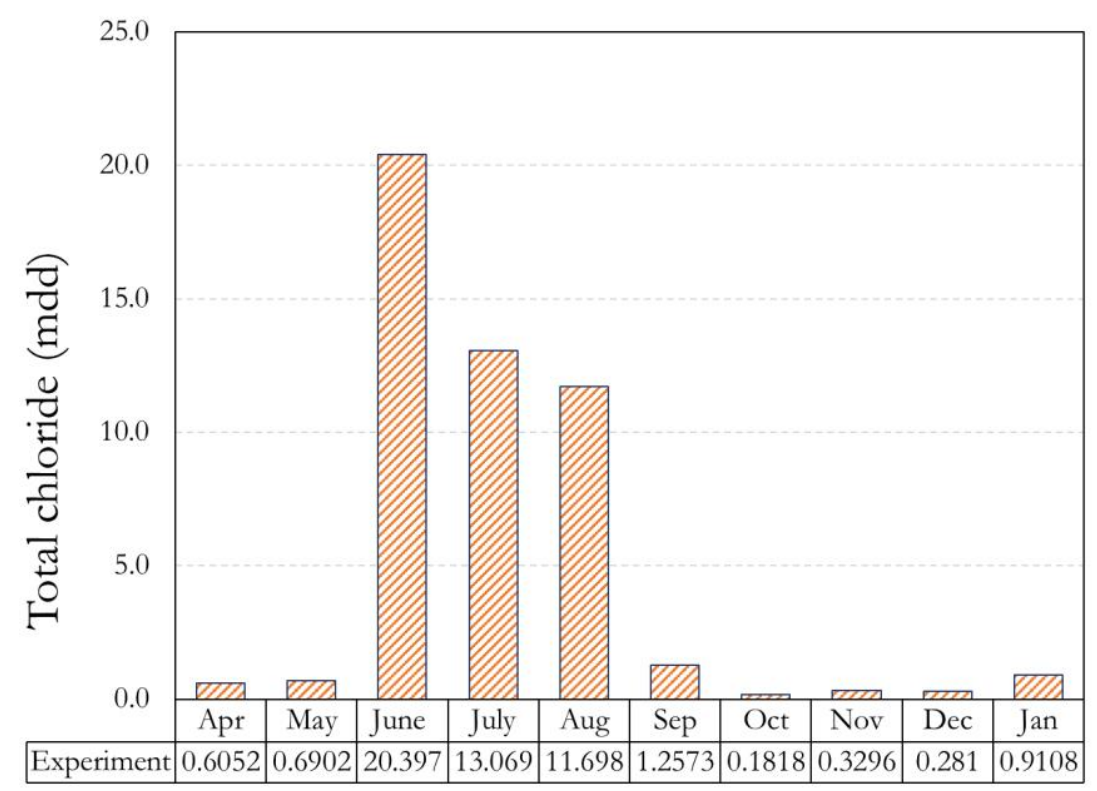

Fig. 16. Airborne chloride in Chonburi.

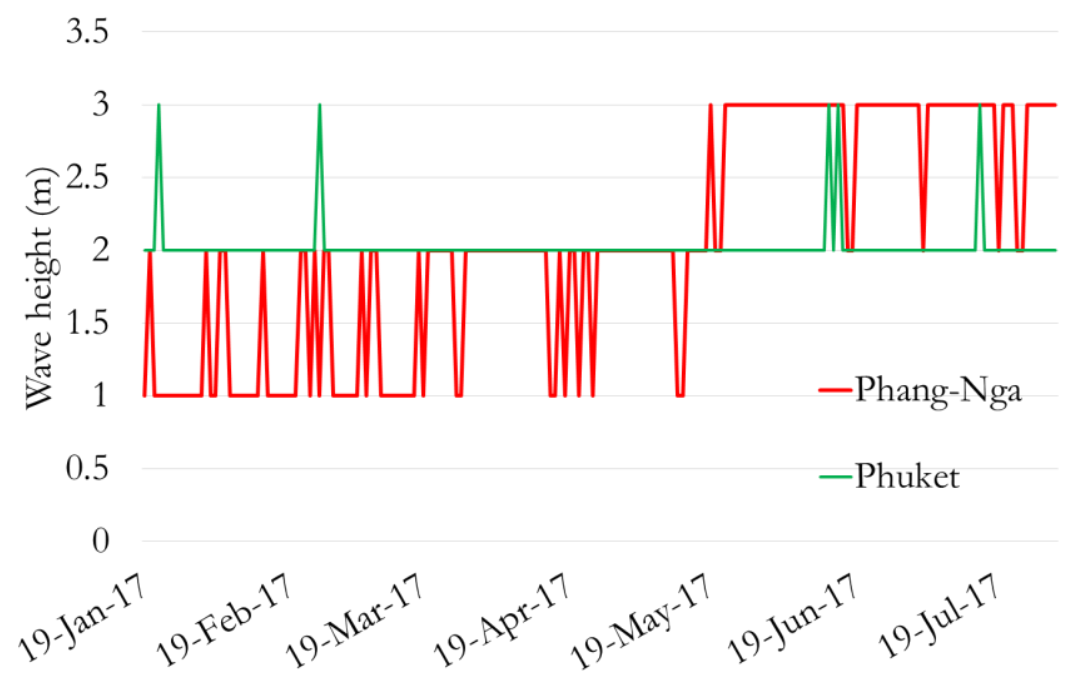

Fig. 17. Wave height in Phuket and Phang-Nga Province from January to June.

An airborne chloride exposure test was conducted in Niigata, Japan, with the same method in the same period. The amount of airborne chloride in Niigata, Japan, from January to February 2017 was 12.4 mdd [31] while PhangNga and Phuket recorded value between around 0.5-0.6 mdd in the same period. It can be inferred that the amount of airborne chloride in Thailand differed from that in Japan owing to their different exposure and climate conditions.

4.1.5. The comparison of ABS amount in Chonburi and Phang-Nga (April-December 2018)

Previous studies show that the salinity in the Gulf of Thailand is around $3.0-3.2 \%$ [19], which is very close to the value in the Andaman Sea. Thus, the comparison will focus on climate and environmental conditions. Figure 18 shows the ABS amount in Chonburi and Phang-Nga, where the exposure conditions are almost the same.

It is seen that the amount of ABS is higher from June to August owing to higher breaking wave heights. However, the amount of ABS in Phang-Nga and Chonburi from June to August differed significantly. The weekly weather report by the Thai Meteorological Department reported higher rainfall in Chonburi than in Phang-Nga in June [20]. In August, heavy rain was reported in the Phang-Nga area but low rainfall in the Chonburi area [21]. This may be the cause of variance in the ABS value in each area. 


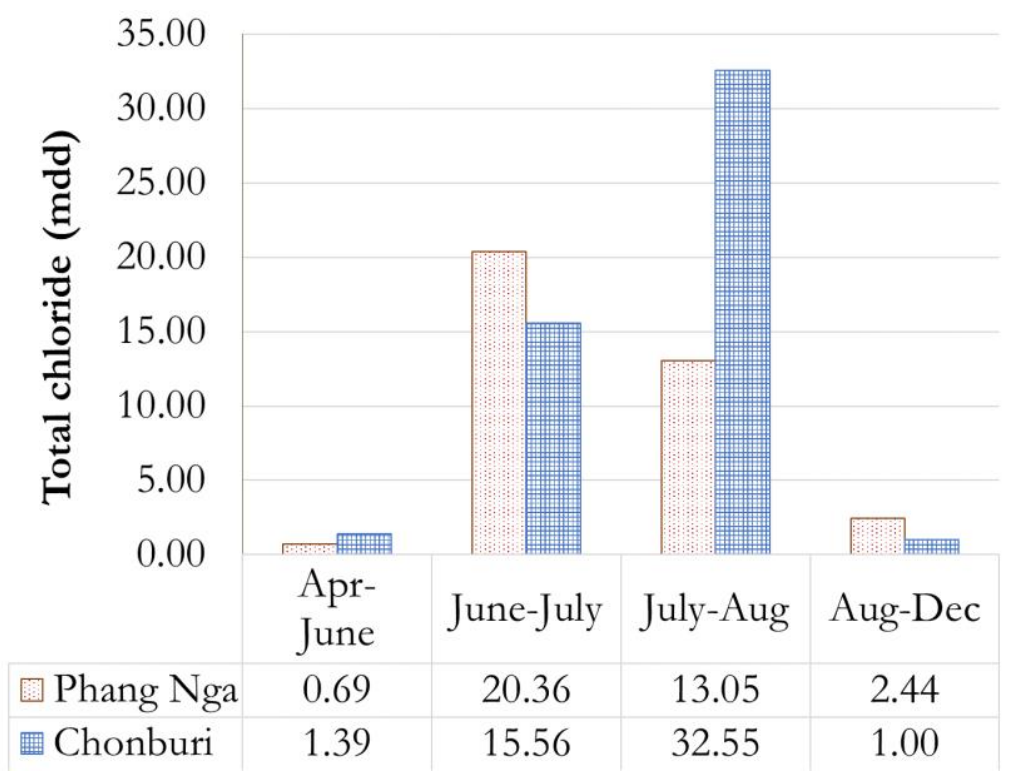

Fig. 18. Amount of ABS in Chonburi and Phang-Nga Province during April-December 2018.

\subsection{Airborne Chloride Penetration}

The results of airborne chloride penetration from on-site measurements are shown in Figs. 19-22. In three months, the amount of airborne chloride penetration in each mix design is almost the same. However, at $1.5 \mathrm{~cm}$, the amount of chloride penetration in the OPC mix is slightly higher. Additionally, the amount of chloride in the BLCP mix proportion is marginally higher than the others. The results may be due to the different pozzolanic reaction rates between different sources of fly ash [22]. Previous studies show that the reaction between fly ash and alkaline solutions in cement paste can differ even though the amount of silica and alumina in fly ash is almost the same [23]. BLCP fly ash may have a smaller initial pozzolanic reaction than Japanese and Mae Moh FA, which makes the chloride penetration greater.

Figure 20 shows that the amount of chloride at 0.75 $1.75 \mathrm{~cm}$ in each mix is higher than that in the three-month specimen. At $1.75 \mathrm{~cm}$ depth, the OPC mix and Mae Moh mix have a higher amount of chloride. Besides, BLCP and Japanese fly ash have a lower amount of chloride. At this stage, although the fly ash is classified as the same class, the amount of chloride penetration differed.

After nine months (Fig. 21), the results are still in the same trend as the six-month exposure. At $1.75-\mathrm{cm}$ depth, the OPC and Mae Moh mixture has a higher amount of chloride. However, the amount of chloride at $0.25 \mathrm{~cm}$ in each specimen is lower than that at $0.75-\mathrm{cm}$ depth. This may be due to the washout effect during the rain [17], which reduces the chloride close to the specimen surface.

After 12 months (Fig. 22), one sample was lost during the monsoon period while the overall chloride amount was unchanged. This may be because of the reduction of airborne chloride from January to March.

From Fig. 19 to 22, it can be seen that chloride ions continuously ingress into the materials by diffusion $[24,25$, 26]. However, airborne chloride concertation on the surface was found to have reduced potentially owing to the washout effect of rainfall [12, 27]. Water particles from rainfall or melted snow wash chloride from the concrete surfaces $[1,27,28]$ resulting in a change in the amount of chloride on the surface during the experiment.

The mortar specimen with Japanese fly ash $30 \%$, at $0.75 \mathrm{~cm}$ depth, contains higher total chloride content than the $100 \%$ OPC cement specimens at the same water to binder level. This may be because the pozzolanic reaction in the fly ash specimen produces additional calcium silicate hydrate (C-S-H) product to fill up capillary pores, making the porosity of the fly ash concrete differ from normal concrete [29]. Additionally, the amount of bind chloride in fly ash concrete was higher than the normal cement paste [30]. As a result, the chloride could not penetrate deeper.

In the six-month and nine-month specimens, the mortar with BLCP FA had lower total chloride content inside the specimen $(0.75-1.75 \mathrm{~cm}$ depth) than the mortar with Mae Moh and Japanese FA. One of the reasons could be the difference in fineness. Table 1 shows that the fly ash from BLCP has higher fineness air permeability, indicating smaller particles compared to Mae Moh and Japanese FA. Thus, the smaller particle can act as a filter inside the mortar specimen and make the sample denser. However, as the result can be affected by many factors, such as the human error in the specimen preparation process and the consistency of fly ash, additional experiments are needed to clarify the result. 




Fig. 19. Comparison of airborne chloride penetration in each mix design (3 months).



Fig. 20. Comparison of salt-water penetration in each mix design (6 months).

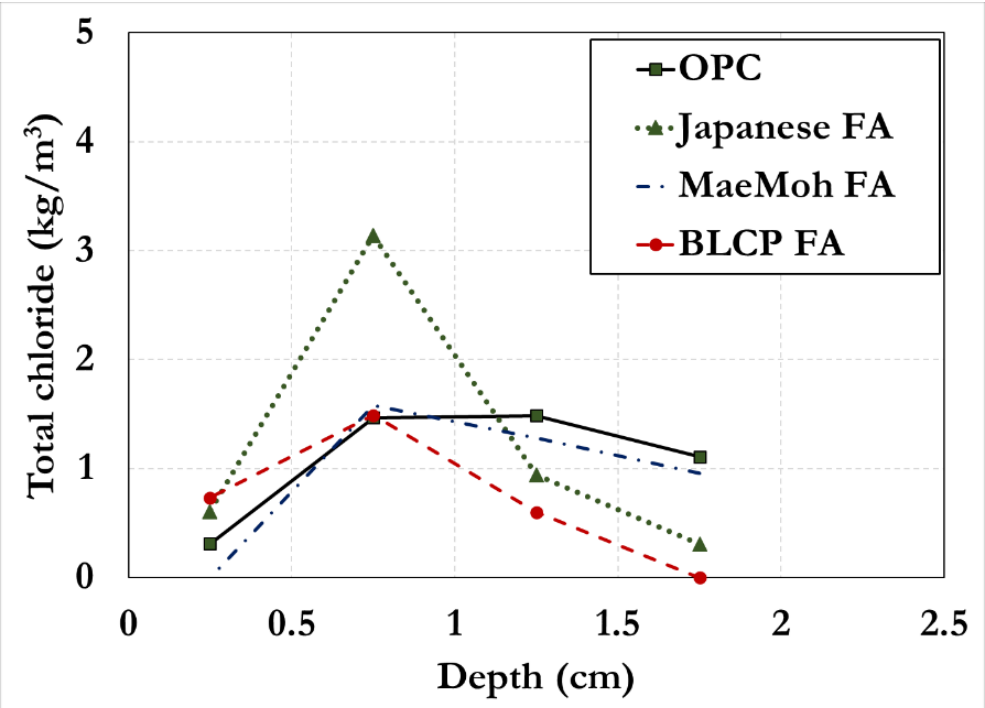

Fig. 21. Comparison of salt-water penetration in each mix design ( 9 months). 


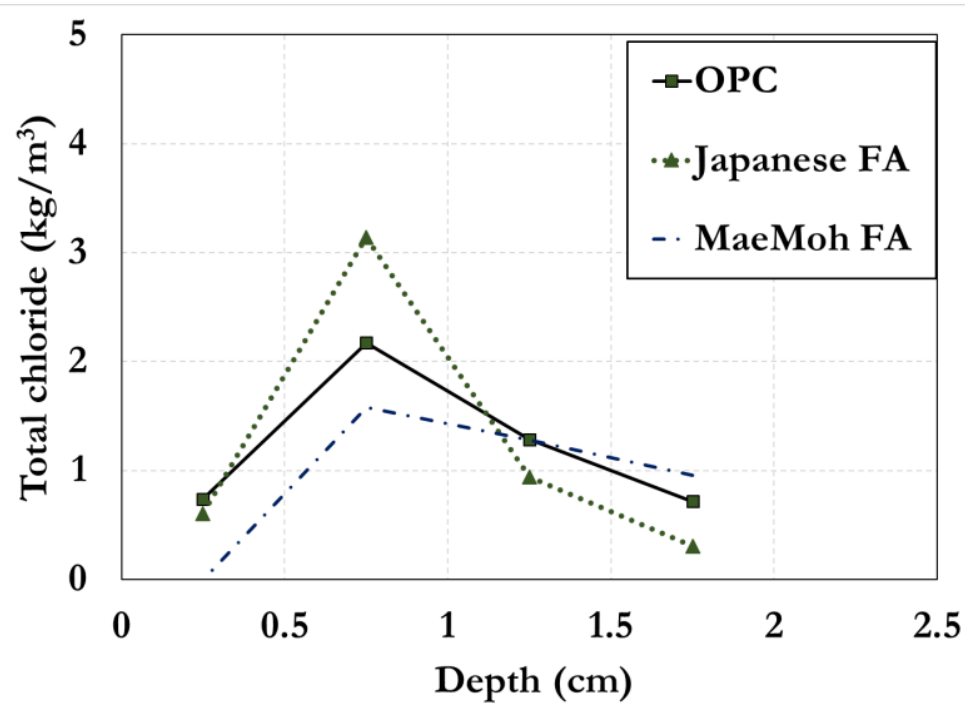

Fig. 22. Comparison of salt-water penetration in each mix design (12 months).

\section{Conclusion}

It is essential to carefully consider the amount of airborne chloride and the concrete mix proportions while designing concrete structures in airborne chloride environments. From the onsite exposure, it can be inferred that the amount of airborne chloride differs owing to weather and breaking wave height and the amount of airborne chloride in Southern and Eastern Thailand in each season. However, in this study, the exposure duration in some areas were limited, highlighting the need for additional tests to successfully assess the level of airborne chloride in Thailand.

The chloride penetration rate under airborne chloride conditions changes when using different types of fly ash. Airborne chloride on the concrete surface did not increase for 3 to 12 months potentially owing to the rainfall. Additionally, different mix proportions may have different chloride binding capacities, which affects the chloride penetration level. Fly ash can be considered as the additive material that can reduce the chloride penetration and prolong the corrosion rate in concrete. However, different sources of fly ash provide different results. Additional tests should be conducted to assess the potential of each mix design.

\section{Acknowledgements}

The authors would like to acknowledge the support provided by the Concrete and Materials Testing Laboratory, Faculty of Engineering, Chulalongkorn University, and Concrete Laboratory, University of Tokyo. This research is supported by Ratchadapisek Somphot Fund for Postdoctoral Fellowship, Chulalongkorn University.

\section{References}

[1] S. Swatekititham, "Computational model for chloride concentration at surface of concrete under actual environmental condition," The dissertation, Kochi University of Technology, Kochi, Japan, 2004.

[2] N. Bongochgetsakul, S. Kokubo, and S. Nasu, "Measurement of Airborne Chloride Particle Sizes Distribution for Infrastructures Maintenance," in IESL-SSMS Joint Symposium, Colombo, Srilanka, 2011.

[3] A. M. Y. Mohammed, A. Ahmed, and K. Maekawa, "Seismic evaluation of coastal RC building vulnerable to an airborne," in Proceedings of the International Conference on Ageing of Materials \& Structures, Delft, Netherlands, 2014.

[4] S. Kokubo and H. Okamura, "Calculation model for airborne chloride ion based on seawater particle generation," JSCE Journal of Hydraulic, Coastal and Environmental Engineering, vol. 65, pp. 259-268, 2009.

[5] Public Work Research Institute, "Report on investigation of airborne chloride in Japan (III), PWRI report No. 2687, 1988.

[6] F. Nakamura, M. Ikuta, T. Shimomura, and T. Hosoyamada, "Field observation and numerical analysis on the adhesion of airborne chloride on concrete surface," in Proceedings of the Japan Concrete Institute, Tamatsu, 2014.

[7] G. R. Meira, M. C. Andrade, I. J. Padaratz, M. C. Alonso, and J. C. Borba Jr., "Measurements and modelling of marine salt transportation and deposition in a tropical region in Brazil," Atmospheric Environment, vol. 40, no. 29, pp. 5596-5607, 2006.

[8] K. M. Hossain and S. M. Easa, "Spatial distribution of marine salts in coastal region," International Journal of Recent Research and Applied Studies, vol. 7, no. 3, pp. 228 - 235, 2011. 
[9] M. Mustafa and K. Yusof, "Atmospheric chloride penetration into concrete in semi-tropical marine environment," Cement and Concrete Research, vol. 24, no. 4, pp. 661-670, 1994.

[10] T. Saeki, M. Takeda, K. Sasaki, and T. Shima, "Study on quantitative estimation of aerosol chlorides condition," in Proceedings of Japan Society of Civil Engineers, Hokkaido, Japan, 2010.

[11] Y.-S. Chen, H.-J. Chiu, Y.-W. Chan, Y.-C. Chang, and C.-C. Yang, "The correlation between air-borne salt and chlorides cumulated on concrete surface in the marine atmosphere zone in North Taiwan," Journal of Marine Science Technology, vol. 21, no. 1, pp. 24-34, 2013.

[12] R. Wattanapornprom and T. Ishida, "Modeling of chloride penetration into concrete under airborne chloride environmental conditions combined with washout effects," Journal of Advanced Concrete Technology, vol. 15, pp. 126-142, March 2017.

[13] Y. Hosoi, R. Wattanapornprom, T. Ishida, and Y. Takahashi, "Validation of airborne chloride generation and transportation model based on site measurement for 27 months by two methods," in JCI Annual Convention, Sendai, Japan, 2017.

[14] T. Ishida, A. Kita, S. Hanioka, L. A. Ho Thi, and Y. Matsuda, "A study on mechanism of airborne chloride transport and migration into mortar based on onsite measurement," in Proceedings of the Concrete Structure Scenarios, 2012.

[15] Standard Test Method for Acid-Soluble Chloride in Mortar and Concrete, A. C. /. C1152M, 2012.

[16] Standard Specification for Coal Fly Ash and Raw or Calcined Natural Pozzolan for Use in Concrete, A. C. -. 15, ASTM International, West Conshohocken, PA, 2015

[17] Thai Meteorological Department. (2014). Thai Meteorological Department [Online]. Available: https://www.tmd.go.th/programs/uploads/yearlyS ummary/weather2016.pdf [Accessed 14 September 2017]

[18] K. Rodolfo, "Marine geology of the Andaman Basin, Northeastern Indian Ocean," Marine Geology, vol. 7, pp. 371 - 402, 1969.

[19] P. Sojisuporn, A. Morimoto, and T. Yanagi, "Seasonal variation of sea surface current in the Gulf of Thailand," Coastal Marine Science, vol. 34, no. 1, pp. $1-12,2010$.
[20] Thai Meteorological Department, "Weekly weather report during 9 - 15 July 2018," Thai Meteorological Department, Bangkok, 2018.

[21] Thai Meteorological Department, "Weekly weather report during 30 July - 5 August 2018," Thai Meteorological Department, Bangkok, 2018.

[22] T. Wang, T. Ishida, and G. Rui, "A comparison of the specific surface area of fly ash measured by image analysis with conventional methods," Construction and Building Materials, vol. 190, pp. 1163 - 1172, 2018.

[23] T. Wang, "Modeling of pozzolanic reaction of siliceous fly ash in cement system based on its material characterization," The University of Tokyo, Tokyo, 2017.

[24] P. Mehta, Concrete in the Marine Environment. Taylor \& Francis Books, Inc, 2003.

[25] E. Poulsen and L. Mejlbro, Diffusion of Chloride in Concrete: Theory and Application. Taylor \& Francis Inc., 2006, pp. 10-11.

[26] P. O. Iqbal, "Chloride transport coupled with moisture migration in non-saturated concrete exposed to marine environment and application to cracked concrete," The University of Tokyo, Tokyo, 2008.

[27] H. Yamashita, T. Shimomura, and F. Yamada, "Study of chloride concentration on concrete surface affected by airborne chloride," in Japan Concrete Institute Annual Conference, Japan, 2007.

[28] M. I. El-Desouky and T. Tsubaki, "Durability improvement of concrete structures by wash-away of chloride," Society for Social Management Systems Internet Journal, May 2012.

[29] M. Narmluk and T. Nawa, "Effect of curing temperature on pozzolanic reaction of fly ash in blended cement paste," International Journal of Chemical Engineering and Applications, vol. 5, no. 1, pp. 31 - 35, Feburary 2014.

[30] T. Sumranwanich and S. Tangtermsirikul, "A model for predicting time-dependent chloride binding capacity of cement-fly ash cementitious system," Materials and Structures, vol. 37, pp. 387 - 396, 2004.

[31] R. Wattanapornprom and T. Ishida, "Comprehensive numerical system for predicting airborne chloride generation and its ingress in concrete under actual environmental conditions," Journal of Advanced Concrete Technology, vol. 16, no. 1, pp. 18 - 35, 2018. 


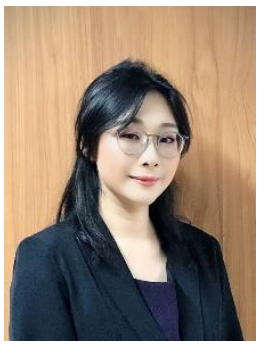

Rungrawee Wattanapornprom was born in Bangkok, Thailand in 1987. She received the B.Eng. in civil engineering from Chulalongkorn University, Bangkok and the B.B.A., in construction management from Sukothaithammatirach Open University, Nonthaburi, Thailand, in 2009. In 2012, she received M.Sc. in technopreneurship and innovation management from Chulalongkorn University, Thailand and D.Eng. in civil engineering from the University of Tokyo, Japan, in 2016.

From 2009 to 2012, she was an engineer in the product development department in Concrete Product and Aggregate Company co.,Itd (CPAC) under Siam Cement Group (SCG), Thailand. From 2016 to 2018, she was a postdoctoral researcher at the University of Tokyo, Japan. From 2018 to 2019, she was a postdoctoral researcher in the Innovative Construction Materials Research Unit of Chulalongkorn University. Her research interests include the innovation of construction materials, durability of concrete and recycled materials on concrete properties.

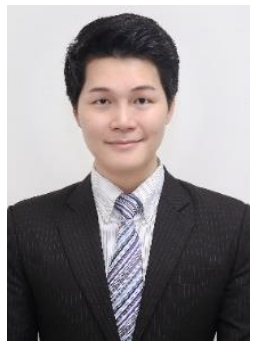

Pakpoom Limtong was born in 1994, Thailand. He received his B.Eng. in civil engineering in 2016 from Chulalongkorn University, Thailand, and his M.Eng. in civil engineering in 2019 from the University of Tokyo, Japan. From 2019, He continues pursuing a Ph.D. degree in civil engineering at the University of Tokyo.

He has been working on modeling of concrete durability performance focusing on water and chloride transport in unsaturated concrete with and without supplementary cementitious materials $(\mathrm{SCMs})$. His research interests include the capillary suction mechanism of unsaturated concrete subjected to external condensed liquid water.

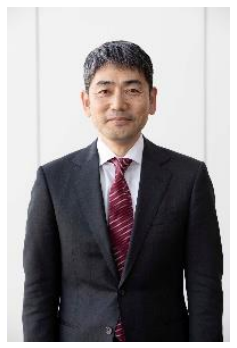

Tetsuya Ishida was born in 1971. He received his B.Eng. in Civil Engineering in 1994 and M.Eng in 1996 from the University of Tokyo, Japan. After receiving a Ph.D. from the University of Tokyo in 1999, he was appointed as an Assistant Professor at the University of Tokyo.

From 1999 to 2001, he visited the University of Toronto, as a post-doctoral research fellow supported by the Japan Society for the Promotion of Science, and in 2003, he was promoted to an Associate Professor at the University of Tokyo. In 2013, he became a full Professor at the University of Tokyo.

He was a recipient of many awards and prizes from JSCE, JCI, SSMS, fib. He also won IABSE prize at the opening ceremony of the 33rd IABSE Symposium in 2009. He has been working on the development of the Finite-Element based computational platform, thermodynamics of cementitious materials and Civil Engineering materials in general; non-linear mechanics of aging concrete; modeling of concrete durability performance; maintenance management of infrastructure stock.

Phoonsak Pheinsusom, photograph and biography not available at the time of publication.

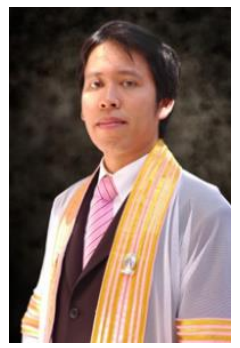

Withit Pansuk was born in Bangkok, Thailand in 1981. He received the B.Eng. in civil engineering from Chulalongkorn University, Thailand, in 2002 and the M.Eng. and Ph.D. in structural engineering from Hokkaido University, Japan, in 2007.

From 2008, he was a lecturer in civil engineering at the faculty of engineering, Chulalongkorn University. Since 2015, he has been an associate professor with the civil engineering department, faculty of engineering, Chulalongkorn University. $\mathrm{He}$ is one of the founding members of the Innovative Construction Materials Research Unit of Chulalongkorn University. His research interests include protections of construction materials, design, and construction of 3-D printed structures and investigation of infrastructures by UAVs \& Big Data Analysis. 